\title{
ANÍSIO TEIXEIRA NA DIREÇÃO DO INEP: PROGRAMA PARA A RECONSTRUÇẢ̃O DA NAÇÃO BRASILEIRA (1952-1964)*
}

RAQUel Gandini*

E

m 2002, Marta de Araújo e Iria Brzezinski solicitaram a membros do Grupo de Trabalho "História da Educação", da Associação Nacional de Pós-Graduação e Pesquisa em Educação (ANPEd), a realização de investigações com o objetivo de "mapear", em "cada estado da federação, os vínculos dos projetos, planos, experiências educacionais e reformas de ensino com o Programa de Reconstrução Educacional" (p. 7). As organizadoras da coletânea são pesquisadoras renomadas: Marta Maria de Araújo, da Universidade Federal do Rio Grande do Norte (UFRN), é autora de muitas publicações e, entre elas, pesquisas sobre Anísio Teixeira. Iria Brzezinski, docente da Universidade Católica de Goiás (UCG), dedica-se predominantemente a estudos sobre formação de professores. Ambas assinam dois artigos do livro: a primeira discorre sobre a atuação de Anísio no Rio Grande do Norte e Brzezinski discute o Instituto de Educação de Goiás.

O livro compõe-se de doze capítulos, resultantes das pesquisas realizadas nos estados do Rio Grande do Sul, Paraná, Santa Catarina, Rio de Janeiro, Minas Gerais, Bahia, Goiás, Sergipe, Maranhão e Rio Grande do Norte. A maioria dos autores trabalha em universidades federais dos estados onde realizaram as pesquisas. Cinco dos doze capítulos têm mais de um autor, professores doutores, mestres e estudantes de cursos de graduação.

* Resenha do livro organizado por Marta Maria de Araújo e Iria Brzezinski (Brasília: Instituto Nacional de Estudos e Pesquisas Educacionais Anísio Teixeira, 2006. 288p.).

** Livre-docente pela Universidade Estadual de Campinas (UnICAMP) e professora do Programa de Pós-Graduação em Educação da Universidade Metodista de Piracicaba (UnimeP). E-mail: raquelgandini@uol.com.br 
Trata-se de um alentado volume, cujos capítulos são bastante heterogêneos em relação a vários aspectos: tipos de tratamento dispensado ao tema, períodos históricos distintos entre si e daquele apresentado no título da coletânea e deslocamentos do assunto principal. Apresenta muitas informações que poderão ser úteis para quem se interessar pela atuação de Anísio Teixeira como diretor do Instituto Nacional de Estudos Pedagógicos (INEP) nos diferentes estados focalizados pelos pesquisadores.

Inicialmente, cabe observar a ausência de um esclarecimento sobre o subtítulo do livro: Programa para a reconstrução da naçāo brasileira. As organizadoras afirmam na Apresentação (p. 7) que a sua intenção era "explicitar as políticas projetadas em articulação com o Programa de Reconstrução Educacional, pensado e executado por Anísio Teixeira, como diretor-geral do Instituto Nacional de Estudos Pedagógicos INEP (1952-1964)". O referido "Programa", que não diz respeito à $\mathrm{Na}$ ção, mas se limita à educação, também não foi apresentado. O leitor irá encontrar esclarecimentos sobre o subtítulo do livro no último capítulo, de autoria Marta Maria de Araújo, mas sobre um Plano de reconstrução educacional.

Marta Araújo trata do seguinte tema: "Uma ousada reforma educacional do governo Dinarte Mariz no Rio Grande do Norte (19561961) e o apoio institucional de Anísio Teixeira como diretor do INEP". A Autora tem o cuidado de apresentar inicialmente algumas informaçôes que situam o leitor acerca do assunto principal da coletânea e também de seu próprio texto. Entre outros subsídios importantes, relata que Anísio realmente apresentou, mas em 1953, o Plano de Reconstrução Educacional do INEP, cujas principais iniciativas foram: a Campanha de Inquérito e Levantamento do Ensino Médio e Elementar (CILEME) e a Campanha do Livro Didático e Manuais de Ensino (CAlDEME). Em 1955, essas campanhas foram substituídas pela criação do Centro Brasileiro de Pesquisas Educacionais (СВPE) no Rio de Janeiro, em colaboração com a UNESCO, e dos Centros Regionais de Pesquisas Educacionais (CRPE) no Rio Grande do Sul, São Paulo, Minas Gerais, Bahia e Pernambuco (Araújo, 2006, p. 252-253).

As finalidades dos Centros eram as seguintes, dentre outras, segundo Araújo (ibid., p. 253):

1) pesquisar as condiçóes culturais, escolares e tendências do desenvolvimento regional para a definição de uma política educacional diversificada; elabo- 
Anísio Teixeira na direção do INEP: programa para a reconstrução da nação brasileira...

rar material pedagógico, incluindo o livro didático; realizar estudos especiais na área de Currículo, Psicologia, Sociologia, Arte Infantil, Orientação Educacional, Supervisão e Administração escolar; promover cursos e treinamentos intensivos para professores, especialistas e administradores que concorressem para um magistério menos empírico e mais científico pela adoção de procedimentos metodológicos, experimentais, investigativos e técnicos no ato de ensinar, dentre outras.

Porém, a chave principal da reorganização pretendida seria o aperfeiçoamento do professor "em vista do ato de ensinar e educar por meio de procedimentos técnicos e científicos" (idem, ibid., p. 253).

Embora as finalidades dos Centros e a pretensão principal da reorganização fossem relevantes e bem programadas, a informação fundamental que possibilita o entendimento do alto nível que Anísio Teixeira conseguiu imprimir ao seu trabalho encontra-se no seu poder, enquanto diretor do INEP, de alocar as verbas necessárias.

Araújo apresenta detalhadamente essa informação às páginas 255 e 256. Trata-se de um percurso que começa em 1942 com a criação do Fundo Nacional de Ensino Primário (FNEP). Segue com a criação, por intermédio do INEP, do Programa de Cooperação Financeira às Unidades Federativas em 1946, com recursos do FNEP, chegando a 1947, quando foi estendido às escolas normais e secundárias públicas e particulares do país. Inicialmente, o Programa destinava-se à construção de prédios escolares, mas, em 1955, quando Anísio era diretor do INEP, os critérios de distribuição dos recursos foram modificados, passando a considerar não somente o déficit de matrícula da população em idade escolar, mas também os progressos nos índices da escolarização primária e média (idem, ibid., p.255-256).

Em muitos capítulos, o leitor sente falta de informações sobre o período estudado. Assim, para exemplificar, o importante Decreto n. 38.460, de 28/12/1955, que institucionalizou os CRPEs e o CBPE, reproduzido às páginas 122 e 123 da coletânea, foi assinado por Nereu Ramos, vice-presidente do Senado Federal, no exercício do cargo de presidente da República. A quem Nereu Ramos substituía e por quê?

Uma outra observação sobre a maioria dos capítulos diz respeito às pessoas que, nos diferentes estados, muito contribuíram para os bons resultados da atuação de Anísio Teixeira. Os autores relatam esses trabalhos, mas ao final destacam e elogiam apenas o diretor do INEP. Esse 
é o caso da competente professora Pórcia Guimarães Alves, cujos textos serviram como fonte para as pesquisas sobre o Centro Educacional Guaíra, que são apresentadas no segundo e terceiro capítulos, de autoria de Marcus Levy Albino Bencostta, da UFPR, e Bento Mossorunga. Este último, diga-se de passagem, não é identificado profissionalmente e nem tampouco mencionado na Apresentação.

A bibliografia de Mossorunga apresenta quatro textos da professora Pórcia G. Alves, destacando-se, entre eles, uma tese apresentada na antiga Faculdade de Filosofia da Universidade Federal do Paraná: Contribuição ao estudo da repetência escolar (Curitiba, 1961. 51f.), na qual ela apontava causas administrativas, metodológicas, biológicas, sociais e financeiras da repetência, segundo relato do autor. Pórcia organizou uma das primeiras classes especiais para atender crianças "excepcionais", mas que participavam das atividades de recreação comuns às demais crianças; criou um projeto de carteiras escolares que foi adotado posteriormente pelo INEP para todo o Brasil, entre outras muitas iniciativas. Não teria Pórcia Guimarães Alves, ainda que uma "inepiana”, se destacado mais do que Anísio Teixeira no caso do Centro Educacional Guaíra? As pesquisas podem apresentar resultados não esperados...

O primeiro capítulo - "Luzes e sombra de um projeto. O Programa de Reconstrução Educacional de Anísio Teixeira no Rio Grande do Sul (1952-1964)" - confunde o leitor, que se pergunta sobre os critérios de sua organização, a partir de seu título. Um competente relato sobre a atuação de Anísio no Rio Grande do Sul encontra-se na primeira parte, de autoria de Maria H.C. Bastos (PUC-RS). A segunda parte, assinada por Claudemir de Quadros (UNIFRA-RS), tem como tema central as realizações do então governador Leonel Brizola no período de 1959 a 1963, quando ele construiu mais de mil prédios escolares no Rio Grande do Sul. O autor, que resume nesse texto a sua dissertação de mestrado, não registra a participação de Anísio e nem do INEP na obra de Brizola. A terceira parte, de autoria de Rosimar Esquinsani (UCS-RS), apresenta o debate entre Anísio Teixeira e os opositores à intervenção do Estado na educação, liderados pela Igreja Católica. Esquinsani baseia-se em sua dissertação de mestrado sobre o mesmo tema. Constata-se que não se trata de um texto, mas de três, sendo que os dois últimos não dizem respeito aos títulos do capítulo e do livro.

Destacam-se positivamente na coletânea os seguintes capítulos: "Educação como reconstituição da experiência: Guatemala, a escola-la- 
boratório do INEP", de Yolanda Lima Lobo (UENF) e Miriam Waidenfeld Chaves (UfRJ); "Escolas-parque: legado do educador Anísio Teixeira, patrimônio da educação brasileira”, de Alice Fátima Martins. Este último, além de bem escrito, apresenta detalhadamente ao leitor as escolas-parque e possibilita a avaliação da importância material e conceitual das mesmas, que foram, com todo o mérito, consideradas patrimônio cultural imaterial da educação brasileira. O texto de Anamaria Gonçalves Bueno de Freitas e Jorge Carvalho do Nascimento, ambos da UFS, também merece destaque porque registra o poder de Anísio Teixeira de alocar verbas; segundo, sublinha a interferência de políticas locais e, terceiro, destaca a importância de José Antonio Nunes Mendonça na educação sergipana, baseando-se em um trabalho de Josefa Eliana Souza sobre a trajetória do mesmo. Muitos capítulos contam com ilustrações que enriquecem as informações apresentadas.

Finalmente, cabe observar que o livro infelizmente apresenta muitas falhas de ordem editorial. A ausência de revisão cuidadosa resultou em erros de ortografia, de gramática, descumprimento das normas da $\mathrm{ABNT}$, além de diversidade do padrão gráfico. Uma nova edição mereceria uma revisão minuciosa. 